\title{
Khuff Sequence KS6: Paleorelief-influenced Facies and Sequence Patterns in the Lower Khuff Formation, Sultanate of Oman
}

Daniel Bendias (University of Tübingen $<$ daniel.bendias@gmail.com>), Thomas Aigner (University of Tübingen), Michael Pöppelreiter (Shell) and Bastian Köhrer (Wintershall)

This outcrop analog study of Lower Khuff Sequence KS6 (Saiq Formation) aims to capture lateral reservoir facies distribution during the initial phase of basin-fill. The Hercynian tectonic event triggered the erosion of Cambrian to Carboniferous strata in Oman and formed the topography of the Sub-Khuff Unconformity. When the Neo-Tethys Ocean flooded the Arabian Shield clastic sediments, the so-called "Basal Khuff Clastics" became preferentially deposited in possible paleo-lows. One main objective of this study was to unravel the effect of this paleo-relief on reservoir facies distribution within the overlying sediments.

The lowermost Khuff Sequence 6 (KS 6) can be subdivided into four different facies associations (backshoal, shoal, foreshoal and offshoal) with distinct sedimentological characteristics and reservoir potential. The KS6 represents one transgressive-regressive cycle. In contrast to younger Khuff sequences (KS4 to KS1) the underlying paleo-relief seems to strongly affect the thickness and facies composition of the KS6 and the Basal Khuff Clastics.

\section{Workflow and Methods}

The concept of dynamic stratigraphy (Aigner, 1985; Aigner et al. 1998; Kerans and Tinker 1997) guided this study from 1-D sedimentological observations in the field to 2-D correlation to the final 3-D model (Figure 1).

1-D: Three months of intense fieldwork led to detailed logs of five sections of the KS6 Sequence. The 1-D dataset includes Dunham textures, outcrop gamma-ray and microfacies data provided by more than 200 thin sections.

2-D: Facies cycles, outcrop gamma-ray and biostratigraphy were used to create several correlation scenarios.

3-D: In order to delineate strengths and weaknesses of the different 3-D geocellular modelling approaches, a broad spectrum of modelling methods was tested. Finally a range of models was generated based on the "Truncated Gaussian with trends" algorithm using different correlation scenarios and varying lateral extents of reservoir facies types (Figure 2).

\section{Conclusions}

The initial paleo-relief apparently controlled the thickness of the initial Khuff clastics, and that of the overlying KS6 carbonates as well as their composition. The correlation strategy to follow paleo-landscape surfaces using all available data resulted in a "pseudo-layer cake" stratigraphic architecture with subtle shingles. This study revealed potential reservoir units in the KS6, commonly regarded as non-reservoir in the subsurface of Oman. In the transgressive part of the investigated sequence, the predominant reservoir facies are bioclastic crinoidal grainstones with only poor diagenetic potential, concentrated around the margin of a paleohigh. Oolitic/peloidal grainstones in the upper regressive part have a much higher diagenetic potential and are areally much more widespread. Abundance and lateral extent of individual grainstones strongly vary with stratigraphic position. Within the palaeo-geographic framework of a shoal to offshoal setting, the thickest and laterally most persistent shoal bodies occur during peak regression. 


\section{References}

Aigner, T., Heinz, J., Hornung, J., Asprion, U. [1998] A hierarchical process-approach to reservoir heterogeneity: examples from outcrop analogues. Bulletin du Centre de Recherches Elf Exploration Production, 22, 1, 1-11.

Kerans, C., Tinker, S. W. [1997] Sequence stratigraphy and characterization of carbonate reservoirs. SEPM Short Course Notes, no. 40, 130 p.

Koehrer, B., M. Zeller, T. Aigner, M. Poeppelreiter, P. Milroy, H. Forke and S. Al-Kindi 2010. Facies and stratigraphic framework of a Khuff outcrop equivalent: Saiq and Mahil formations, Al Jabal al-Akhdar, Sultanate of Oman. GeoArabia, v. 15, no. 2, p. 91-156.

Koehrer, B., T. Aigner and M. Poeppelreiter 2011. Field-scale geometries of Upper Khuff reservoir geobodies in an outcrop analogue (Oman Mountains, Sultanate of Oman). Petroleum Geoscience, v. 17, no. 1, p. 3-16.

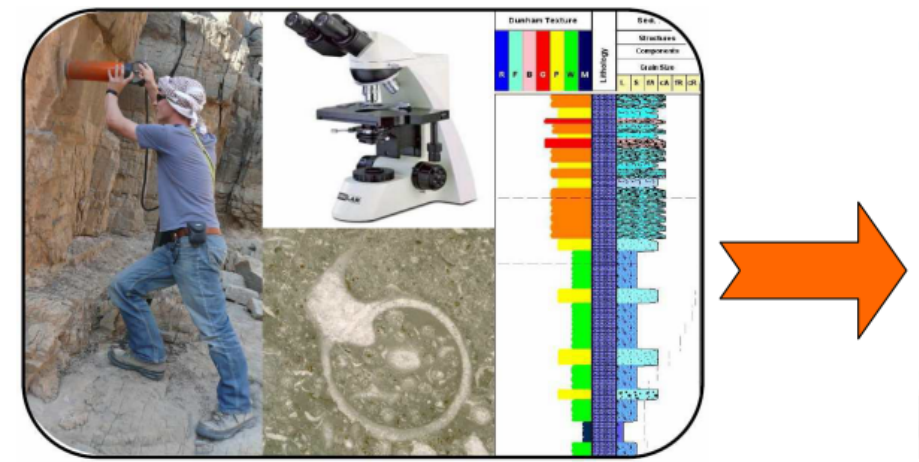

1D Sedimentological Observation

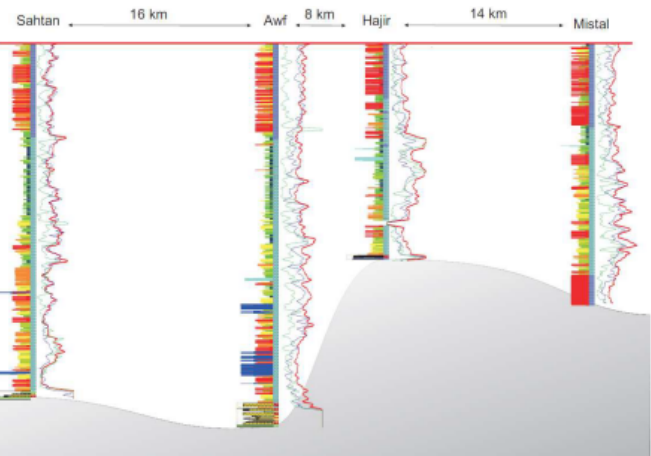

2D Correlation
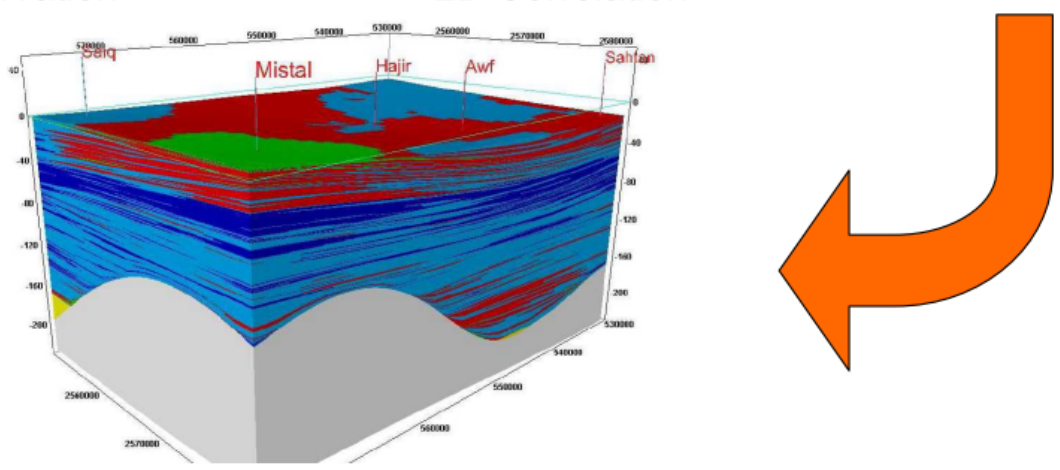

3D Modelling

Figure 1: Workflow from 1-D sedimentological observation in the field to 2-D correlation, with obvious changes in thickness between the sections and 3-D modeling. 


\section{EAGE}

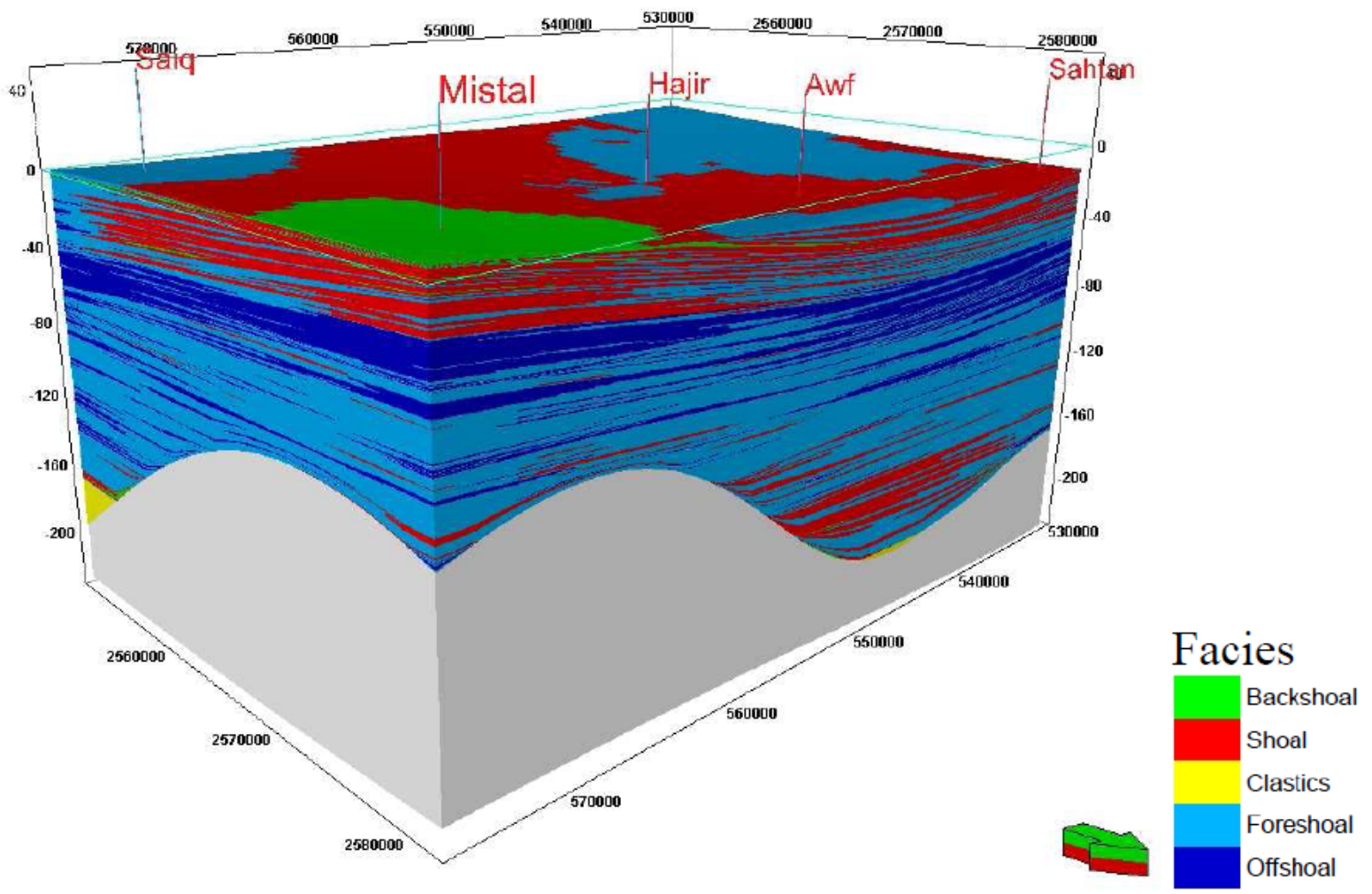

Figure 2: Facies model generated with Truncated Gaussian with trends method, view from northeast. Potential reservoir facies is displayed in red. 